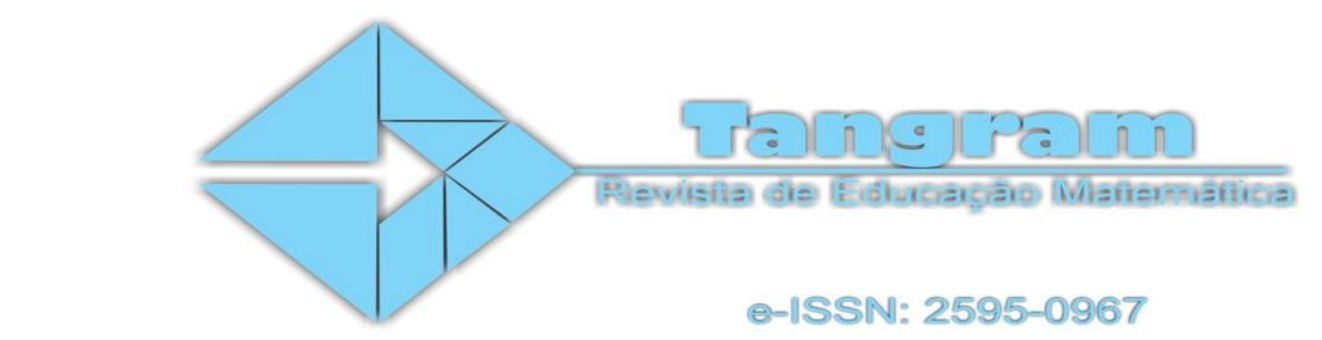

\title{
Cenários animados no GeoGebra e o estudo de funções por alunos com altas habilidades/superdotação
}

\section{Animated scenarios in GeoGebra and the study of functions by high skills/giftedness students}

\section{Escenarios animados en GeoGebra y el estudio de funciones por estudiantes con altas habilidades / superdotación}

\author{
Adrieli Cristine Bueno \\ Universidade Estadual do Paraná -Campus de União da Vitória \\ União da Vitória, Brasil \\ adrielicbueno@gmail.com \\ Orcid: 0000-0001-5363-4099 \\ Maria Ivete Basniak \\ Universidade Estadual do Paraná -Campus de União da Vitória \\ União da Vitória, Brasil \\ basniak2000@yahoo.com.br \\ Orcid: 0000-0001-5172-981X
}

Enviado:20/08/2020

Aceito:24/03/2021

DOI: 10.30612/tangram.v4i1.12629

\begin{abstract}
Resumo: Um software que se destaca para o ensino da Matemática é o GeoGebra, por permitir reflexões e investigações sobre representações feitas. Os alunos com Altas Habilidades/Superdotação (AH/SD) necessitam de tarefas que explorem suas capacidades. Neste contexto, este trabalho teve como objetivo investigar as contribuições da construção de cenários animados no software GeoGebra para a o ensino e aprendizagem de funções de primeiro grau a alunos com AH/SD da Sala de Recursos Multifuncional (SRM). Para tanto a pesquisa assume como método o estudo de caso de cunho investigativo interpretativo, em que analisamos a partir de registros um episódio de aula referente a construção do cenário animado de um submarino submergindo e depois emergindo do fundo do mar. Verificamos apropriações dos alunos em relação a domínio e comportamento de funções do primeiro grau por meio das construções no software, suportados pelas mediações do professor para a significação dos conteúdos de matemática.
\end{abstract}

Palavras-chave: Tecnologias digitas. Altas Habilidades/ Superdotação. Funções.

Tangram - Revista de Educação Matemática, Dourados - MS - v.4 n.1, pp. 134-154 (2021) 


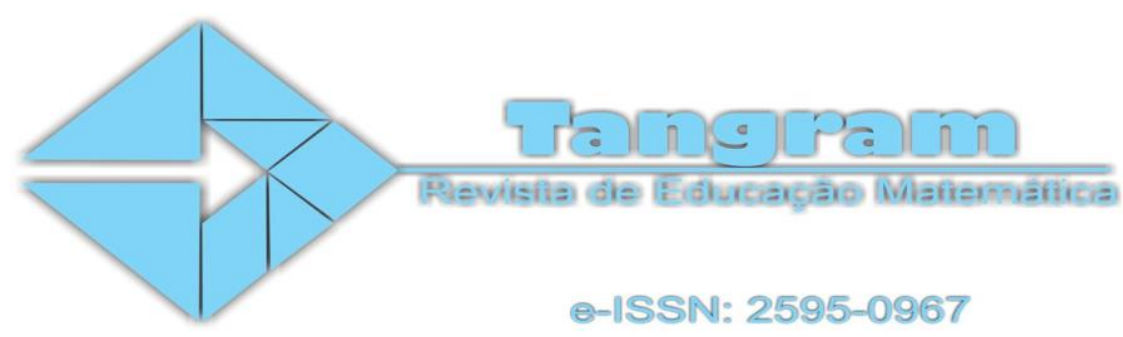

\begin{abstract}
A software that stands out for mathematics teaching is the GeoGebra, for allowing reflections and investigations on the representations made. The High Skilled/Giftedness students need tasks that explore their abilities. In this context, this research had as objective investigate the contributions of the construction of animated scenarios in the software GeoGebra for the teaching and learning of linear function to Skilled/Giftedness students from the Multifunctional Resources Room. Therefore the research assumes as method the case study of investigative and interpretative nature, in which we analyze from records a class episode regarding the animated scenario building of a submarine submerging and then emerging from the ocean floor. We verified appropriations from the students in regards to the domain and the behavior of linear functions through the constructions in the software, supported by the teacher's mediations for the meaning of the mathematical contents.
\end{abstract}

Keywords: Digital Technologies. High Skilled/Giftedness. Functions.

Resumen: Un software que se destaca para la enseñanza de las matemáticas es GeoGebra, por permitir reflexiones e investigaciones sobre las representaciones realizadas. Los estudiantes con altas habilidades / superdotación (AH / SD) necesitan tareas que exploren sus capacidades. En este contexto, este trabajo tuvo como objetivo investigar las contribuciones de construcción de escenarios animados en el software GeoGebra para la enseñanza y aprendizaje de funciones de primer grado a estudiantes con AH / SD de la Sala de Recursos Multifuncional (SRM). Para ello, la investigación asume el uso de un estudio de caso investigativo interpretativo, que analizamos a partir de los registros, un episodio de clase referente a la construcción del escenario animado de un submarino sumergiéndose y después emergiendo del fondo del mar. Verificamos las apropiaciones de los estudiantes en relación al dominio y comportamiento de las funciones de primer grado a través de las construcciones en el software, apoyados por las mediaciones del profesor para el significado de los contenidos matemáticos.

Palabras clave: Tecnologías digitales. Altas habilidades / Superdotación. Funciones.

\title{
Introdução
}

Uma das concepções mais conhecidas sobre o superdotado é de que seria aquele indivíduo que se sai bem em todos os testes de inteligência ou que apresenta um desempenho intelectual superior (Fleith, 2006). No entanto, somente essas características não são suficientes para determinar se uma pessoa é superdotada ou não, porque Altas

Tangram - Revista de Educação Matemática, Dourados - MS - v.4 n.1, pp. 134-154 (2021) 


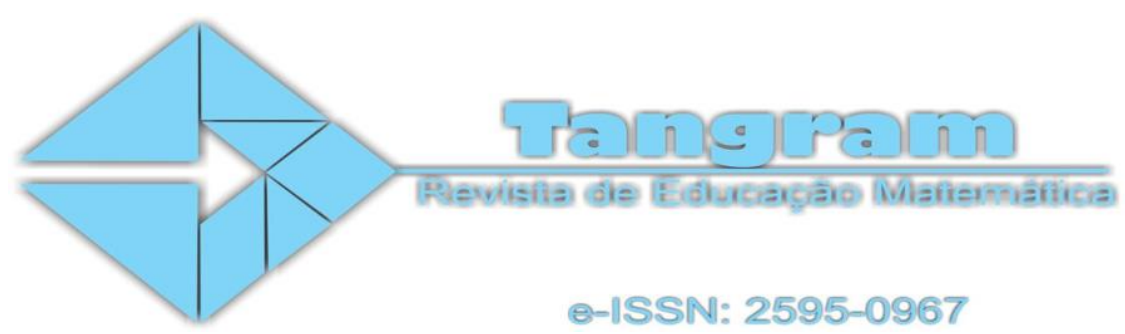

Habilidades/Superdotação (AH/SD) não é necessariamente sinônimo de Quociente de Inteligência (QI) alto (Renzulli, 1978). Entre as características dos alunos que apresentam ou desenvolvem AH/SD, Renzulli (1978) destaca a aptidão acadêmica e o pensamento criativo. Para Virgolim (2007), AH/SD pode suceder-se em inúmeras áreas do conhecimento humano, seja intelectual, social, artística, entre outras, em um continuum de habilidades. Possuir AH/SD pode auxiliar para um desempenho excelente ou levar esses indivíduos a se sentirem desmotivados e entediados com a escola, pois eles precisam ser desafiados continuamente, o que nem sempre ocorre nas salas de aula (Fleith, 2006). Quando uma pessoa possui $\mathrm{AH} / \mathrm{SD}$, ela demonstra um desempenho superior em uma determinada área do conhecimento, o que não significa que ela apresente o mesmo desempenho nas demais, ou seja, pode manifestar dificuldades em outras áreas (Mendonça, Zavitoski e Capellini, 2013).

Logo, o trabalho com os alunos com AH/SD precisa ser diferente do habitual, porque eles necessitam de tarefas que explorem suas capacidades, agucem o gosto por pesquisar e desenvolvam o seu raciocino lógico, não ficando somente em tarefas repetitivas e monótonas (Guimarães e Mello, 2006). Neste sentido, Delpretto e Zardo (2010, p. 23) destacam que "projetos de trabalho pela sua natureza flexível, enriquecedora e exploratória, organizados na perspectiva inclusiva, são capazes de instigar a aprendizagem por descoberta e criação".

Segundo os Parâmetros Curriculares Nacionais (Brasil, 2006) existem softwares nos quais os alunos podem explorar e construir diferentes conceitos matemáticos e que apresentam recursos que provocam, de forma muito natural, o processo que caracteriza o pensar matematicamente, ou seja, permitem os alunos fazerem experimentos, testarem hipóteses, esboçarem conjecturas e criarem estratégias para resolver problemas.

Atualmente um dos softwares que se destaca no contexto do ensino da Matemática é o GeoGebra, software livre e gratuito de matemática dinâmica que apresenta como principais características sua dinamicidade e facilidade para realizar construções. Esse software permite a construção de objetos utilizando as ferramentas nele disponíveis ou utilizando comandos inseridos na caixa de entrada. Por exemplo, para a construção de uma

Tangram - Revista de Educação Matemática, Dourados - MS - v.4 n.1, pp. 134-154 (2021) 


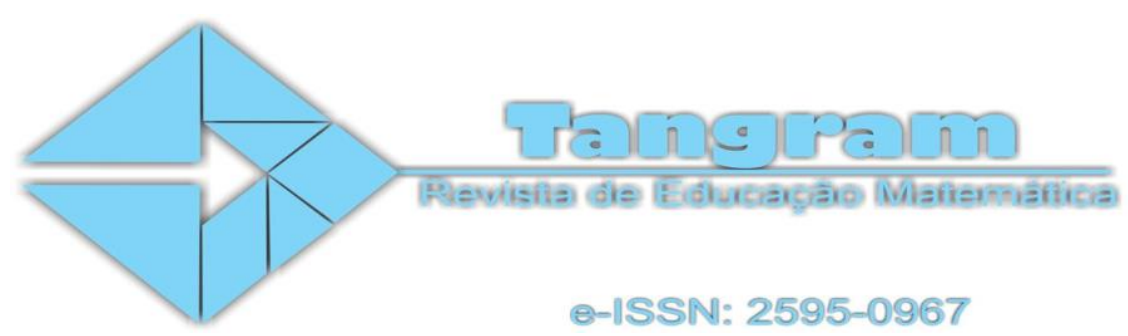

circunferência centrada na origem do plano cartesiano e com raio igual a 3, o aluno pode plotar a equação que a descreve $x^{2}+y^{2}=9$, ou clicar no ícone, círculo dados centro e raio.

Dessa forma, realizar construções de objetos no GeoGebra, utilizando conceitos da matemática, permite que os alunos reflitam sobre representações feitas, o que requer um constante processo de investigação acerca dos objetos matemáticos que podem ser utilizados na construção.

Assim, ao realizar a construção destes objetos podem emergir investigações e discussões sobre as características e particularidades das ferramentas matemáticas envolvidas, bem como sobre a eficácia dessas ferramentas na construção. Tais investigações podem contribuir de maneira significativa para o processo de ensino e aprendizagem de conteúdos matemáticos. Nesta perspectiva, a pesquisa teve como objetivo investigar as contribuições da construção de cenários animados no software GeoGebra, para a o ensino e aprendizagem de funções a alunos com AH/SD de Salas de Recursos Multifuncional (SRM).

Segundo o MEC (Brasil, 2010, p. 6)

As salas de recursos multifuncionais cumprem o propósito da organização de espaços, na própria escola comum, dotados de equipamentos, recursos de acessibilidade e materiais pedagógicos que auxiliam na promoção da escolarização, eliminando barreiras que impedem a plena participação dos alunos público alvo da educação especial, com autonomia e independência, no ambiente educacional e social.

Para atingir o objetivo foi proposto a construção de cenários animados no software GeoGebra abordando o conteúdo de lógica e funções, aos alunos que frequentam a (SRM) de um colégio público estadual de um município no interior do Estado do Paraná. Logo, esta pesquisa será pautada no quadro teórico construído sobre as concepções de AH/SD e as construções de cenários animados no software GeoGebra com os alunos com AH/SD, que aprofundamos na seção que segue.

\section{Algumas concepções de Altas Habilidades/ Superdotação}

Tangram - Revista de Educação Matemática, Dourados - MS - v.4 n.1, pp. 134-154 (2021) 


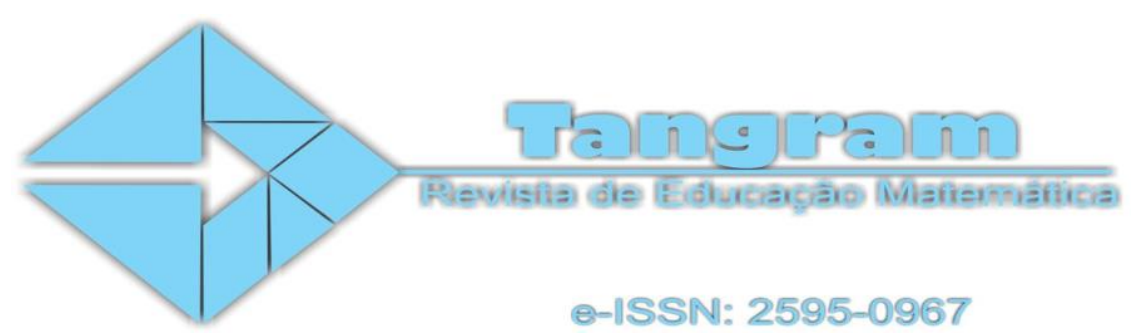

Segundo Virgolim (2007) AH/SD pode suceder-se em inúmeras áreas do conhecimento humano, seja intelectual, social, artística, entre outras, em um continuum de habilidades, em indivíduos com diversos níveis de talento, motivação e conhecimento. Para este autor, as AH/SD são influenciadas por condições genéticas, bem como por fatores do indivíduo, como por exemplo, autoestima elevada, coragem e persistência, associada a fatores culturais como personalidade.

Renzulli (1978) discute as AH/SD a partir da concepção dos Três Anéis, a fim de sugerir diretrizes de programas especiais que favoreçam a evolução cognitiva, desenvolvimento e desempenho de alunos em áreas específicas ou combinadas. Segundo a Teoria dos Três Anéis, há três fatores para que um indivíduo seja diagnosticado com AH/SD: habilidade acima da média, envolvimento com a tarefa e criatividade. Comparado com seus pares, aquele que possui AH/SD demonstra habilidade maior em uma ou mais áreas do conhecimento, ou seja, não necessita apresentar os três requisitos referidos acima, para que seja identificado como apto a desenvolver tais características, porque "as crianças superdotadas e talentosas são aquelas que possuem ou são capazes de desenvolver este conjunto de traços e aplicá-los a qualquer área potencialmente valorizada do desempenho humano" (Renzulli, 1978, p. 261).

A habilidade acima da média se divide em habilidade geral e específica. A habilidade geral refere à competência de empregar o raciocínio abstrato para chegar a respostas que podem ser adaptadas a novas situações. Esta habilidade pode ser medida em testes de inteligência e de aptidão, como o raciocínio verbal e numérico, relações espaciais e fluência verbal. Já a específica refere-se a desenvolver e aplicar várias habilidades a áreas especializadas do conhecimento ou desempenho do ser humano, podendo ser, por exemplo, liderança, composições musicais e dança (Renzulli, 1978).

O envolvimento com a tarefa, segundo o autor, pressupõe a motivação, a energia que a pessoa dispõe para realizar uma tarefa na área de seu interesse, consistindo na perseverança, paciência e concentração que demonstra ao desenvolver o trabalho.

Tangram - Revista de Educação Matemática, Dourados - MS - v.4 n.1, pp. 134-154 (2021) 


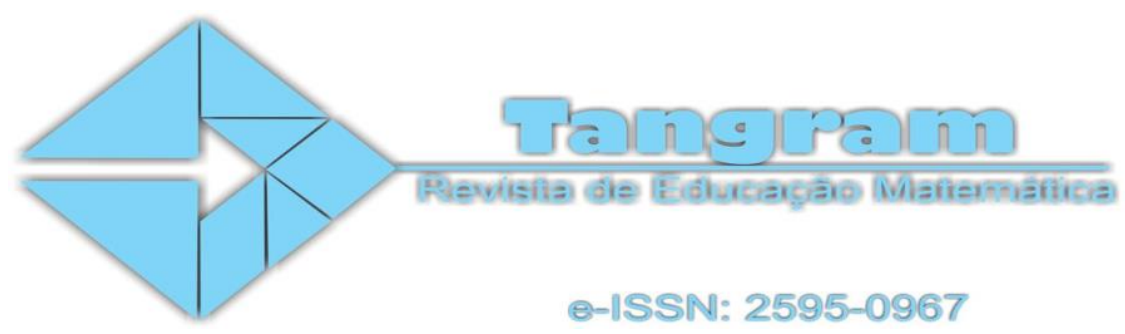

E, segundo Renzulli (1978) a criatividade é destacada como algo determinante na personalidade dos indivíduos, que se destacam em alguma área do conhecimento humano. Arroyo, Martorell e Tarragó (2006, apud Mosquera, Stobäus e Freitas, 2013) argumentam que os superdotados possuem um elevado potencial criativo, mas é difícil medi-lo por meio de testes. A criatividade, para esses três autores, consiste em pensar em algo diferente, algo novo e original, usar ideias de um determinado contexto e desenvolvê-lo em outro, que compreende a capacidade de gerar soluções diferenciadas diante de problemáticas diversas, não deixando dominar-se pelo comum, produzindo novas ideias. Para Virgolim (2007, p. 37) "torna-se um desafio determinar os fatores que levariam o indivíduo a usar seus recursos intelectuais, motivacionais e criativos de forma em produtos de nível superior ou em comportamentos de superdotação".

De acordo com Renzulli (2004) as pessoas criativas e produtivas têm por objetivo, geralmente, causar impacto em um determinado público, e por causa disso buscam energias e o comprometimento com a tarefa.

Os altos níveis de produtividade somente podem ocorrer quando a capacidade acima da média interage com outros fatores, tais como o comprometimento com a tarefa e a criatividade. São estes fatores que permitem que os alunos criem produtos de qualidade excepcional (Renzulli, 2004, p. 90).

Segundo a Política Nacional de Educação Especial na Perspectiva da Educação Inclusiva (Brasil, 2008, p. 15), os alunos com AH/SD são aqueles que "demonstram potencial elevado em qualquer uma das seguintes áreas, isoladas ou combinadas: intelectual, acadêmicas, liderança, psicomotricidade e artes. Também apresentam elevada criatividade, grande envolvimento na aprendizagem, realização de tarefas em áreas de seu interesse".

E de acordo com os Saberes e Práticas da Inclusão (Brasil, 2006), os estudantes com AH/SD são aqueles que apresentam características como: alto grau de curiosidade, boa memória, persistência, autonomia, interesse por áreas e tópicos diversos, facilidade de aprendizagem, criatividade, liderança, podendo ser isoladas ou em conjunto. A Fundação Catarinense de Educação Especial (Santa Catarina, 2011), salienta que os indivíduos com

Tangram - Revista de Educação Matemática, Dourados - MS - v.4 n.1, pp. 134-154 (2021) 


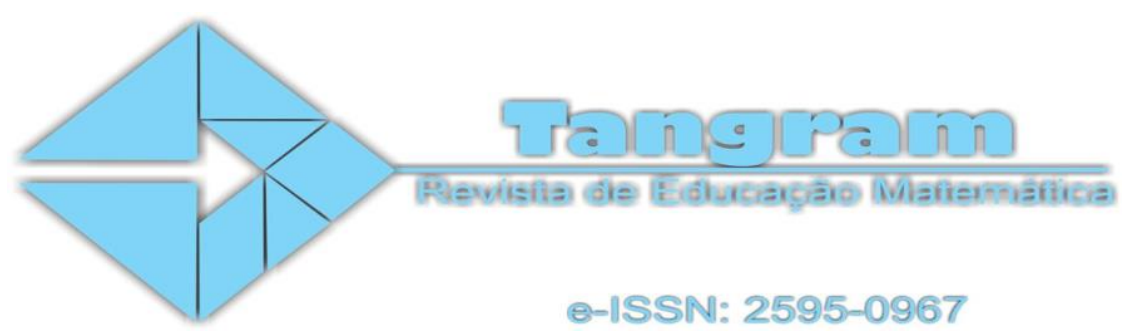

AH/SD geralmente apresentam algumas características peculiares como: desenvolvem a linguagem mais cedo, possuem um alto grau de curiosidade, são criativos, tem uma aprendizagem rápida, são dedicados, possuem boa memória, demonstram interesse por livros, são autônomas (isso não significa que se auto educam), gostam de desafios, entre outros.

A Política Nacional de Educação Especial na Perspectiva da Educação Inclusiva determina que o atendimento educacional especializado nas escolas deve aconteça nas SRM, em que que um professor com formação na área da Educação Especial realize trabalhos complementares com alunos superdotados (Brasil, 2008). Este professor pode buscar apoio e formar parcerias com outros profissionais para que estes alunos tenham oportunidade de desenvolver-se. Neste contexto de parceria entre uma escola e a universidade, nosso trabalho se desenvolve com estes alunos com a construção de cenários animados no software GeoGebra.

\section{O ensino de Matemática e o software GeoGebra}

Onder (2009) afirma que quando o estudante tem a crença de que a Matemática consiste em regras, fórmulas e cálculos deixam-se de lado os aspectos conceituais e o raciocínio lógico, privilegiando o fazer ao pensamento matemático. Essa visão da Matemática pode ser explicada pelo fato de que, raramente em um contexto escolar são propostas situações em que o aluno necessita ser criativo, ou em que seja motivado a solucionar um problema pela curiosidade criada pela situação em si ou pelo desafio do problema proposto, pois "na matemática escolar o aluno não vivencia situações de investigação, exploração e descobrimento" (D’Ambrósio, 1989, p. 16). Evidentemente, tal carência causa limitação nos processos de ensino e aprendizagem da Matemática que, segundo Cyrino e Oliveira (2016), devem ser encarados como processos de inquirição, construídos de forma dialógica e colaborativa que deve:

[...] agregar um valor formativo no que diz respeito ao desenvolvimento do pensamento matemático. Isso significa colocar os alunos em um processo de

Tangram - Revista de Educação Matemática, Dourados - MS - v.4 n.1, pp. 134-154 (2021) 


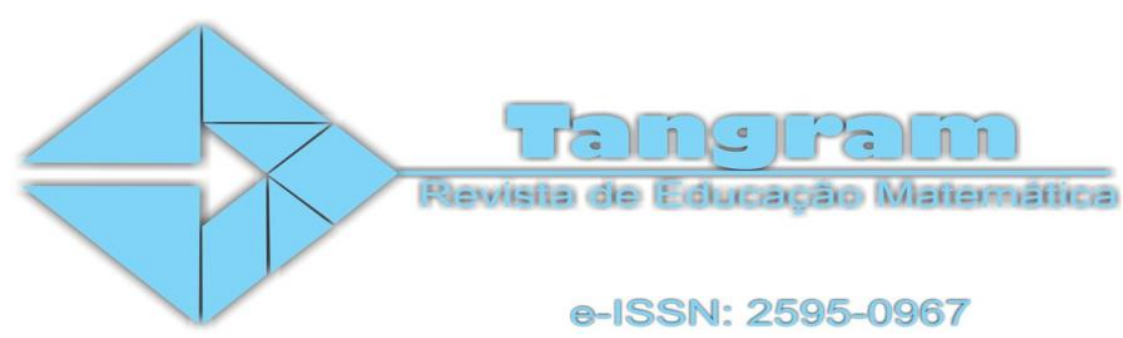

aprendizagem que valorize o raciocínio matemático - nos aspectos de formular questões, perguntar-se sobre a existência de solução, estabelecer hipóteses e tirar conclusões, apresentar exemplos e contraexemplos, generalizar situações, abstrair regularidades, criar modelos, argumentar com fundamentação lógico-dedutiva (Brasil, 2006, p. 70).

Para Cyrino e Oliveira (2016) o ensino deve enfatizar a participação do aluno criando condições que favoreçam a inquirição do aluno, colaborativa e individualmente, porque aquilo que o aluno faz é aquilo que aprende. Assim, o professor deve utilizar as mais variadas ferramentas a fim de garantir a efetivação do processo de inquirição, em que, as tecnologias digitais, em especial o computador, surgem como importante aliado.

Para Valente (1993), o computador pode ser utilizado no processo de ensino de duas formas distintas: máquina de ensinar ou ferramenta educacional. $\mathrm{O}$ computador como máquina de ensino caracteriza-se apenas por computadorizar métodos tradicionais de ensino, sendo usado para mostrar aplicações/representações ou para fixar o conteúdo ensinado anteriormente. Já o computador como ferramenta educacional deixa de ser apenas um instrumento e passa a ser a ferramenta com a qual o aluno aprende, permitindo realizar construções, interação, trabalho colaborativo, processo de descoberta, de forma dinâmica confrontando teoria e prática, aspectos que favorecem o processo de inquirição.

Neste sentido, aportados em Valente (1993), é possível inferir que, principalmente quando se trata da Educação Especial, o computador deve ser utilizado em processos de ensino como ferramenta educacional, de modo a permitir a construção do conhecimento.

Dentre os diversos softwares disponíveis para o ensino de Matemática, destacamos o GeoGebra, desenvolvido por Markus Hohenwarter principalmente para o ensino e aprendizagem de Matemática (Procópio, 2011). Seu nome deriva da aglutinação das palavras Geometria e Álgebra e se caracteriza como um software de Matemática dinâmica, livre e gratuito, que combina álgebra, gráficos, geometria, tabelas, cálculos e estatística. Este software permite a construção de pontos, vetores, segmentos, funções, cônicas e outros objetos matemáticos. Tais construções podem ocorrer de duas diferentes formas: utilizando

Tangram - Revista de Educação Matemática, Dourados - MS - v.4 n.1, pp. 134-154 (2021) 


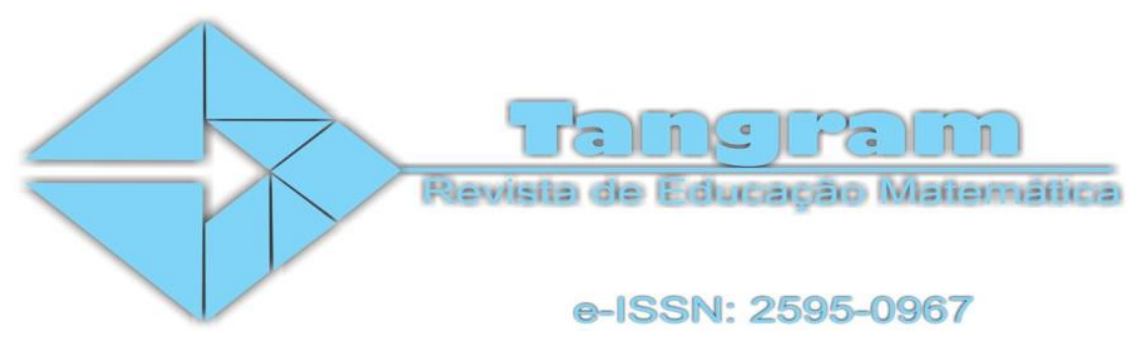

as ferramentas disponíveis no software ou plotando na caixa de entrada as equações/coordenadas do objeto a ser criado.

Outra característica que se destaca neste software é a possibilidade de manipular os objetos criados, o que atribui dinamismo e movimento às construções. Isto está relacionado ao controle deslizante, uma ferramenta que determina uma variável numérica dentro de um intervalo pré-estabelecido pelo operador, que varia de acordo com um incremento, também determinado pelo operador. Logo, neste trabalho definimos os cenários animados no GeoGebra como construções no software, em que elementos matemáticos criados são associados a um controle deslizante que quando animado, garante movimento aos personagens e/ou elementos que caracterizam a cena. A animação do controle deslizante pode ser feita arrastando o controle pelo usuário, alterando seu valor, como desejar, ou ser por meio da seleção da ferramenta animar, que movimentará indefinidamente os objetos, de modo que a produção final constitui um cenário animado. Para a construção destes cenários, um dos conceitos de Matemática que desde o início é muito empregado pelas possibilidades que oferece para a construção dos cenários animados e assim, consideramos necessário abordar inicialmente para o desenvolvimento do trabalho com os alunos foi o conteúdo de funções. Isto porque ao estabelecer relações entre variáveis que serão alteradas por meio de um controle deslizante, é possível tornar uma construção dinâmica, ao associar uma das coordenadas de um ponto ao controle deslizante, variável independente, à outra coordenada, variável dependente, de determinada função. Desta forma, o software GeoGebra permite a construção dos cenários animados com objetos matemáticos, e, são objeto de estudo desta pesquisa, aquelas construídas pelos alunos com AH/SD da SRM, cujo contexto e pressupostos metodológicos apresentamos na próxima seção.

\section{Contexto, pressupostos metodológicos}

A pesquisa é desenvolvida desde meados de 2017, por meio de Projeto de Iniciação Científica. Os episódios analisados referem-se às construções dos cenários animados pelos

Tangram - Revista de Educação Matemática, Dourados - MS - v.4 n.1, pp. 134-154 (2021)

Este obra está licenciada com uma Licença Creative Commons Atribuição-NãoComercial-CompartilhaIgual 3.0 Brasil. 


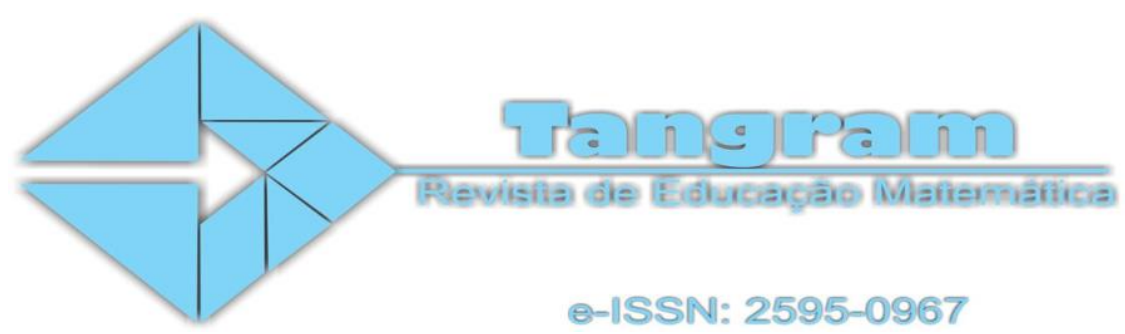

alunos em abril de 2018, quando alguns alunos participavam do projeto há quase um ano e outros haviam ingressado há pouco mais de um mês, devido mudança de ano letivo. Evidenciamos na Tabela 1 essas características. Os nomes dos alunos neste trabalho são fictícios para preservar suas identidades.

Tabela 1: Alunos de 2018

\begin{tabular}{|c|c|c|c|}
\hline ALUNO & ANO ESCOLAR EM 2018 & INÍCIO NO PROJETO & AH/SD \\
\hline ISABELA & $9^{\circ}$ ano & Setembro de 2017 & Linguagem \\
\hline LARA & $9^{\circ}$ ano & Setembro de 2017 & Exatas \\
\hline MIGUEL & $8^{\circ}$ ano & Setembro de 2017 & Exatas \\
\hline WAGNER & $8^{\circ}$ ano & Março de 2018 & Exatas \\
\hline MANUELA & $6^{\circ}$ ano & Março de 2018 & Linguagem \\
\hline JUNIOR & $6^{\circ}$ ano & Março de 2018 & Astronomia/ Linguagem/ Oralidades \\
\hline
\end{tabular}

Antes de iniciar o trabalho com as construções dos cenários animados no GeoGebra, foi realizado acompanhamento na SRM em que se verificou que os alunos com AH/SD gozavam de grande liberdade para desenvolver suas tarefas na SRM. Observamos que as tarefas eram individuais ou em duplas, e o que cada aluno desenvolvia estava relacionado àquilo que demonstrava afinidade e curiosidade. A professora da SRM nos explicou que com estes alunos seu papel é orientá-los e incentivá-los no desenvolvimento de tarefas que partam de seu interesse em desenvolvê-las. Neste sentido, salientamos que a participação de todos os alunos com AH/SD nesta pesquisa parte de seu interesse em participar dos encontros, como apontado por Renzulli (1978), embora alguns não possuam AH/SD em Matemática, como pode ser lido na Tabela 1. Durante este período de observação dos alunos, foram paralelamente planejados alguns cenários animados envolvendo o conteúdo de lógica, sistema cartesiano e funções.

Tangram - Revista de Educação Matemática, Dourados - MS - v.4 n.1, pp. 134-154 (2021) 


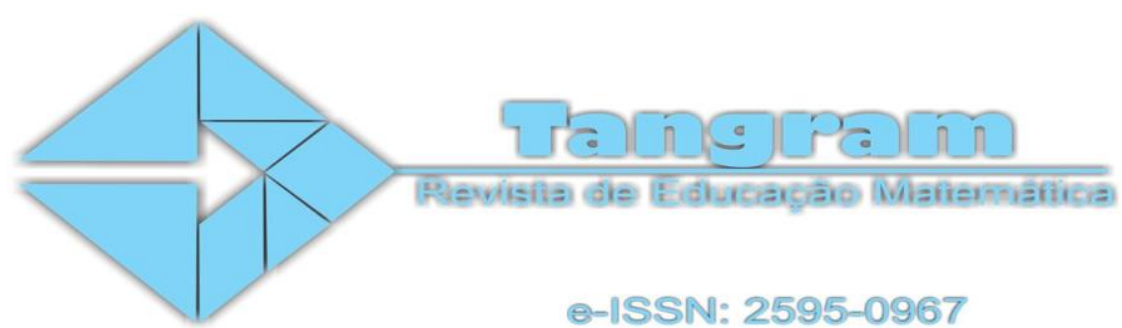

As intervenções iniciaram no final de abril de 2018 e passaram a ser realizadas semanalmente durante um período com duração média de 3 horas. Nas intervenções os cenários animados foram apresentados aos alunos desafiando-os a construí-los, mediados por um ambiente inquiritivo e dialógico em que as pesquisadoras-mediadoras apresentavam algumas possibilidades e questões para que os alunos pudessem formular e testar hipóteses quanto a como construir os cenários, estabelecer e validar conjecturas, bem como a como proceder para construir os cenários. Ao final, os conteúdos utilizados na construção dos cenários foram sistematizados com os alunos.

Neste contexto, esta pesquisa qualitativa de cunho investigativo e interpretativo, assume como método o estudo de caso, que segundo Yin (2001) é uma investigação empírica e que inclui uma técnica de investigação abrangente que segue procedimentos pré especificados, e “[...] como estratégia de pesquisa compreende um método [...] de planejamento incorporando abordagens específicas à coleta de dados e à análise de dados" (Yin, 2001, p.33). Além disso, os estudos de caso se apresentam como "histórias apelativas, verosímeis, credíveis e iluminativas que põem em causa pseudo-verdades tidas como inquestionáveis, ilustram como podem avançar certas inovações, e ajudam a perceber certos aspectos da realidade quotidiana" (Ponte, 2006, p. 20).

Portanto, selecionamos para análise neste trabalho, quatro intervenções que utilizaram o conteúdo de funções como base para as construções e discussões, os quais relatamos brevemente a seguir, a fim de situar o leitor em nossas análises que serão apresentadas na próxima seção.

Na primeira intervenção foi construído junto com os alunos Manuela, Junior e Wagner, que estavam iniciando no projeto, o cenário animado Contagem regressiva, utilizando os conteúdos de lógica e noções do sistema cartesiano. E, aos alunos que participavam do projeto desde 2017, Lara, Isabela e Miguel, foi proposta a construção do cenário animado Submarino $^{1}$, que consiste em um submarino submergindo e depois emergindo do fundo do

${ }^{1}$ A animação pode ser vista em https://www.geogebra.org/m/au3hjxvn

Tangram - Revista de Educação Matemática, Dourados - MS - v.4 n.1, pp. 134-154 (2021) 


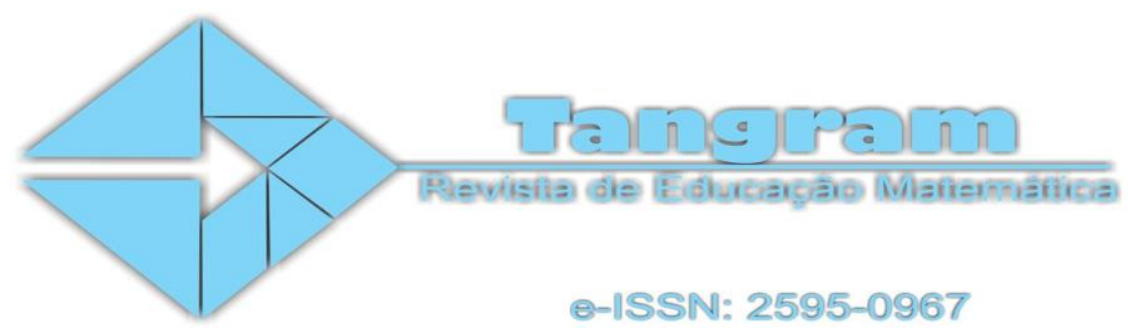

mar (Figura 1), utilizando o conteúdo de funções constante, afim e linear. Isto porque anteriormente observamos que estes alunos, que já participavam da pesquisa, construíam cenários animados utilizando o sistema cartesiano e lógica sem dificuldades, entretanto não tínhamos clareza quanto à sua compreensão do conteúdo funções. Como apresentaram dificuldades na realização da construção, consideramos necessário e oportuno, para a continuidade da pesquisa, retomar este conteúdo com os alunos na segunda intervenção, a fim de discutir conceitos importantes com aqueles que já participavam e introduzir o conteúdo de funções aos alunos que ingressaram no projeto.

Então na segunda intervenção foi realizada a construção do Submarino (Figura 1) em que foram abordados os conteúdos de função constante, do primeiro grau, desigualdades, coeficientes angular e linear, domínio de uma função e função por partes.

$\mathrm{Na}$ terceira intervenção, foi proposta a construção do cenário animado Trem² (Figura 2), que consiste em um trem se movendo no sentido decrescente do eixo x no plano. Após o trem passar pela cancela ela se abre para que o carro passe. Também há um semáforo que fica vermelho enquanto o trem passa e verde quando o carro pode passar. Para sua construção, além dos conteúdos abordados na construção do submarino foi realizada a programação de dois controles deslizantes a fim de animar os objetos na sequência.

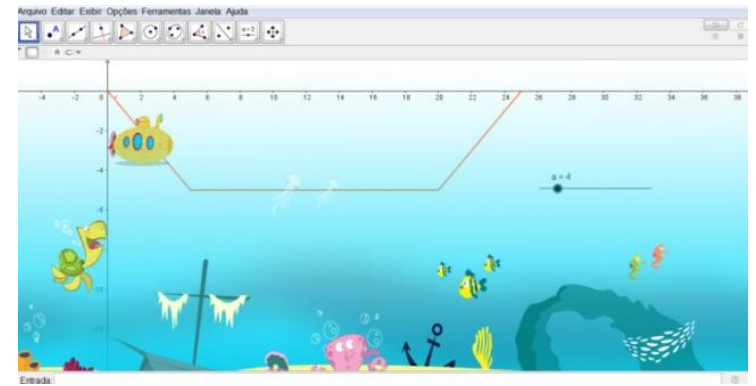

Figura 1 - Cenário animado Submarino Fonte: As autoras, 2020.

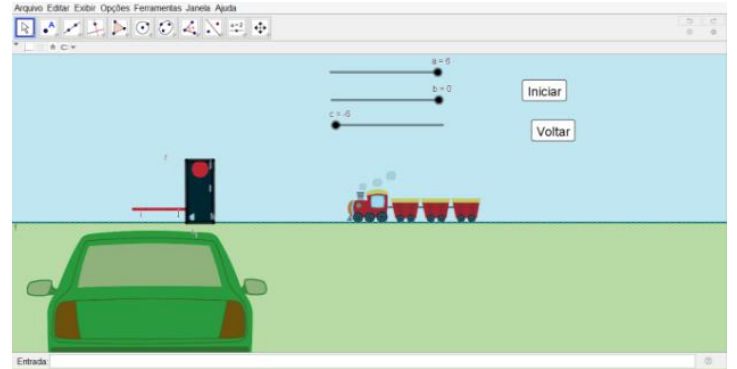

Figura 2 - Cenário animado Trem Fonte: As autoras, 2020.

${ }^{2}$ A animação pode ser vista em https://www.geogebra.org/m/wfydjejz

Tangram - Revista de Educação Matemática, Dourados - MS - v.4 n.1, pp. 134-154 (2021) 


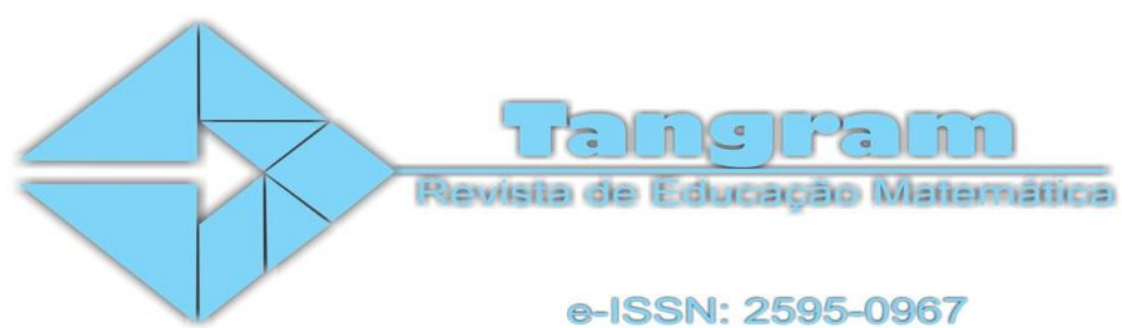

Na quarta intervenção foi realizada a sistematização dos conteúdos utilizados nas construções, nomeadamente: função constante e de primeiro grau abordando as definições de função crescente e decrescente, domínio, imagem, coeficiente angular e linear. Todas as intervenções realizadas com os alunos com $\mathrm{AH} / \mathrm{SD}$ foram registradas por meio de gravações de áudio e das telas do computador das construções realizadas no GeoGebra por meio de software que possibilita tais gravações.

Os três alunos que já participavam da pesquisa haviam construído dois cenários animados utilizando funções do primeiro grau. Mas nenhum dos alunos, tanto os que participaram no segundo semestre de 2017, quanto os que ingressaram em 2018, haviam estudado este conteúdo formalmente na sala de aula regular. Na sequência convidamos estes alunos a explicarem para os acadêmicos da Licenciatura em Matemática como construir o cenário animado Submarino, explicando os conteúdos estudados. Apesar de muito tímidos, ficaram empolgados com a ideia e aceitaram o desafio. Selecionamos a construção apresentada pela aluna Manuela que ingressou no projeto em 2018 e que era do sexto ano do Ensino Fundamental e, portanto, não havia estudado formalmente em sala de aula conteúdos de álgebra, desigualdades e ângulos, que perpassam o conteúdo de funções, especialmente na construção do cenário animado.

Para a análise que apresentamos na seção que segue, selecionamos este episódio de aula, porque neste momento não houve qualquer interferência das pesquisadoras, autoras deste trabalho, complementados por uma intervenção posterior para verificar se os alunos compreenderam os conceitos de funções do primeiro grau, em que responderam algumas questões depois da sistematização dos conteúdos.

\section{Análise do episódio da construção do cenário animado do submarino}

Ao iniciar a construção com os acadêmicos, o excerto a seguir evidencia que a aluna Manuela, mesmo não utilizando os termos corretos, denominando funções como retas ou linhas, consegue escrever a lei de formação de uma função constante corretamente no

Tangram - Revista de Educação Matemática, Dourados - MS - v.4 n.1, pp. 134-154 (2021) 


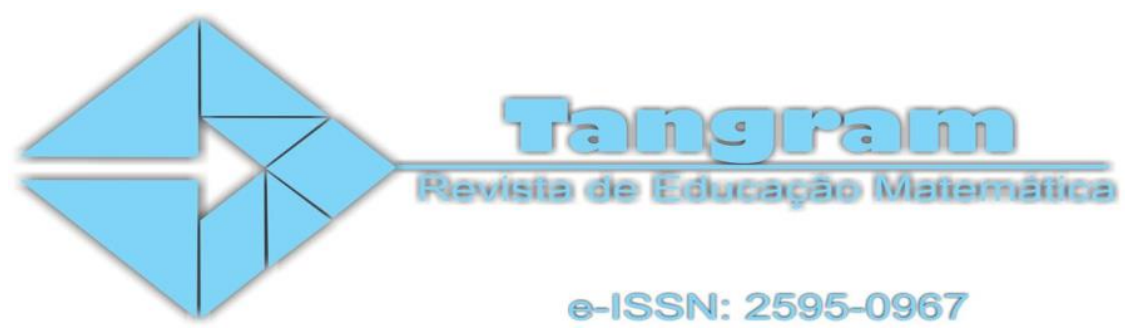

GeoGebra, explicitando seu comportamento em relação ao eixo x, paralela ou coincidente, mais próxima ou distante deste eixo.

Manuela: Eu vou começar criando linhas para o meu submarino andar. Então eu vou aqui na caixa de entrada, eu vou digitar $f$, abre parênteses $x$, colocar igual, vou colocar igual a menos 4 [f(x) $=-4]$, por exemplo, e aí vai ficar aqui no menos 4 [função constante]. Se vocês quiserem colocar menos 3, menos 5, ela vai ficar mais para cima, mais para baixo.

Continuando, para explicar como construir o caminho de descida e subida do submarino do fundo do mar, a aluna Manuela revela que compreendeu o conceito de coeficiente angular, ainda que não lembre o nome correto na hora de explicar, uma vez que por estar no sexto ano do Ensino Fundamental, não estudou ângulos, desigualdades e álgebra. Visto que ela havia se inserido no projeto há menos de dois meses, não foi possível uma discussão mais aprofundada e cuidadosa sobre estes conteúdos. Assim, ela denominou como o número que acompanha o $x$, explicando corretamente o comportamento da função como pode ser lido no excerto a seguir.

Manuela: Agora a gente vai criar uma linha decrescente. Vamos digitar g, abre parênteses, igual a menos $4 x[\mathrm{~g}(\mathrm{x})=-4 \mathrm{x}]$, por exemplo. Se você quiser ela mais inclinada, por exemplo, você pode colocar menos $5 x$ ou menos 3 [inclinação da função, ou seja, coeficiente angular]. Enfim, você que escolhe. A gente vai fazer a mesma coisa do outro lado, só que sem o menos dessa vez $[\mathrm{h}(\mathrm{x})=4 \mathrm{x}]$. Só que elas estão se cruzando [no ponto de origem]. Não vai dar certo, [porque o gráfico das funções crescente e decrescente só poderiam se cruzar em algum ponto abaixo da função constante criada inicialmente] tem que trazer ela mais para cá [para o lado direito] ... vou apagar aqui [a função $\mathrm{h}(\mathrm{x})=4 \mathrm{x}]$.

Na continuidade de sua explicação, nos fornece elementos para discutir sua compreensão de coeficiente linear, que também não denomina corretamente com termos matemáticos, mas revela compreender como este valor interfere no comportamento da função. Ela explica que para as funções não se cruzarem em algum ponto acima da função constante, deve ser diminuído algum valor (neste caso), para que a função intercepte o eixo y em algum ponto abaixo da função constante. Ela também exemplifica que quando esse valor é mais próximo de 0 , a função vai ficar mais para a esquerda, ou seja, mais próximo ao ponto de origem, em

Tangram - Revista de Educação Matemática, Dourados - MS - v.4 n.1, pp. 134-154 (2021)

Este obra está licenciada com uma Licença Creative Commons Atribuição-NãoComercial-CompartilhaIgual 3.0 Brasil. 


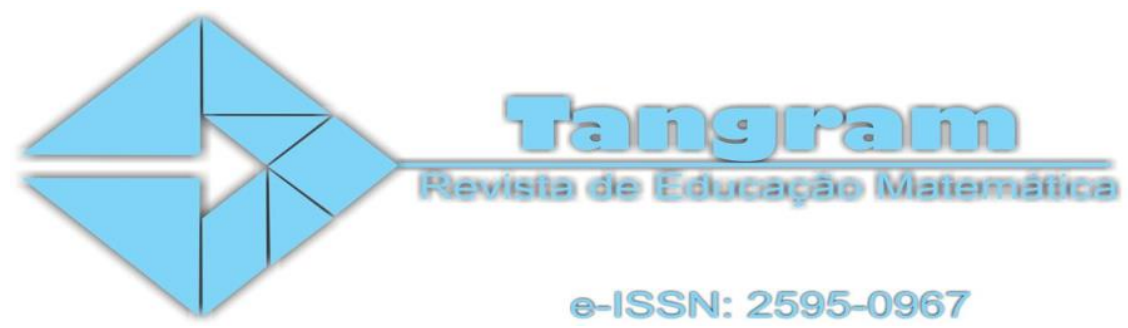

relação ao eixo y. E quando for um valor mais distante de 0 , ficará mais para a direita, mais longe do ponto de origem, em relação ao eixo y.

Manuela: Vocês já podem fazer junto mesmo. $4 x$ menos $44[\mathrm{~h}(\mathrm{x})=4 \mathrm{x}-44]$, por exemplo. Ele vai ficar aqui [mais para a direita no plano]. Quanto menor o número [coeficiente linear], mais próxima da outra linha que a gente criou antes ela vai ficar. Então, se colocar 35, por exemplo, vai ficar mais para o lado, mais para a esquerda. Se colocar 55 vai ficar mais para a direita. Então vocês escolhem o tanto que vocês querem.

Outro conceito relacionado a funções que os alunos estudam formalmente apenas no Ensino Médio e que ao trabalhar com a construção dos cenários animados no GeoGebra utilizam corretamente é o conceito de domínio, necessário (nesta animação) para delimitar o caminho do submarino, ao explicar aos acadêmicos como se deve delimitar o trajeto do submarino, que pode ser lido no excerto a seguir.

Manuela: Depois eu vou ter que definir o tamanho que eu vou querer elas [funções], onde a gente quer que elas fiquem, porque se a gente deixasse assim [como, retas infinitas] vai ficar sobrando para lá e para cá.

Para restringir o domínio é necessário ter conhecimento sobre a desigualdade para escrever a condição da função no GeoGebra, o que é feito digitando na caixa de entrada o comando $\mathrm{Se}(\langle$ Condição $\rangle,\langle$ Então $\rangle)$, como pode ser lido nos excertos a seguir:

\begin{abstract}
Manuela (1): No caso, eu quero que ela [função $\mathrm{f}(\mathrm{x})=-4 \mathrm{x}$ ] fique do zero [ponto de origem] até aqui [coordenada $(1,4)$ ]. A mesma coisa com essas linhas [funções $\mathrm{g}$ e h]. Então, vou criar uma função. Vou na entrada de novo e vou colocar "Se". Vou na primeira alternativa, que é "<Condição $>,<$ Então $>$ ". E vou colocar a minha "condição", que vai ser que ela [domínio da função] fique do zero até aqui [coordenada $(1,4)]$. Só que eu me baseio no eixo $x$. Então vou começar colocando zero, menor ou igual ao eixo $x$, menor ou igual a 1. Por que 1? Porque a minha linha termina no 1. E eu estou me baseando no eixo $x$, então vou colocar 1. [Ficou assim "Se $(0 \leq \mathrm{x} \leq 1,<$ Então $>$ "].
\end{abstract}

Manuela (2): Vou fazer a mesma coisa com a linha $h$ [função $h(x)=4 x-44$ ]. Vou lá, colocar "Se $(<$ Condição $>,\langle$ Então $>)$ ), e vou determinar onde eu quero que ela [função] fique no 11 e 10 [coordenadas $(11,0)$ e $(10,4)]$. Ela vai começar no 11, só que ela vai terminar no 10. E não vai dar certo, porque o GeoGebra não entende. É porque... Então, a gente vai usar o menor ou igual. Então, vai entender [GeoGebra] que é menor a 11. Só que é menor que 10. Então não vai dar certo. Então vou colocar 10 aqui,

Tangram - Revista de Educação Matemática, Dourados - MS - v.4 n.1, pp. 134-154 (2021) 


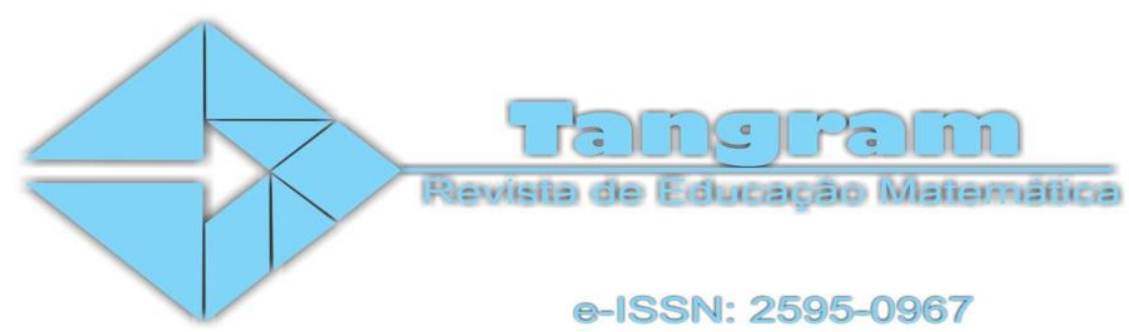

menor ou igual a x, menor ou igual a 11. Que é onde ela termina, no caso começa. Então, vou colocar 11 [Ficou assim "Se $(10 \leq \mathrm{x} \leq 11,<$ Então $>$ "].

No excerto 1 a aluna Manuela consegue estabelecer a conjectura para escrever a condição do domínio, na caixa de entrada do software, e justificar este domínio. Já no relato 2, observamos que a aluna Manuela faz certa confusão ao utilizar as desigualdades e que sua justificativa é que o GeoGebra entende ou não, de forma que revela dificuldade para explicar o sinal da desigualdade e explicar que o maior valor poderia aparecer antes do sinal da desigualdade, só que este sinal teria que estar invertido, ou seja, teria que utilizar maior ou igual e não menor ou igual. Entretanto, no relato 1 revela que compreendeu que para restringir o domínio de uma função é necessário olhar para os pontos no eixo x, e, que caso o domínio fosse definido incorretamente isto reduziria ou excederia o tamanho da função desejada. No excerto a seguir, finaliza sua explicação quanto a restrição da função decrescente, ou seja, limitando o domínio e destacando sobre a sentença da função.

Manuela (continuação do 1): E o meu "então" eu vou olhar lá na minha sentença, o meu $f$ [função], que está menos 4x. Então, eu vou colocar "menos $4 x$ " [Ficou assim " $\mathrm{Se}(0 \leq \mathrm{x} \leq 1,-4 \mathrm{x}]$. Vai criar uma linha somente na parte que eu determinei. Então eu já posso tirar a minha linha $f$ [desabilitar a função f]. Só apertar a bolinha do lado que ela aparece e ela some. E assim, eu determinei onde eu quero que a linha [função] fique. Então, eu vou fazer isso nas outras linhas [funções] a mesma coisa.

Em outro excerto, verificamos a compreensão da aluna Manuela quanto a construção da função por partes, utilizada no trajeto do submarino de modo a facilitar a construção, sendo necessário usar apenas um controle deslizante para isto.

\footnotetext{
Manuela: Agora nós vamos ter que juntar todas essas linhas [funções]. Porque senão vai ter que ter um controle deslizante para cada linha que o submarino for andar. Então a gente vai usar outra função. A gente vai vir aqui na caixa de entrada vai colocar "Se". Só que nós vamos na segunda opção, que é " $<$ Condição $>$, $<$ Então $>$, <Senão $>$ ". A minha "condição" é que ela ande no " $p$ " $[0 \leq \mathrm{x} \leq 1,-4 \mathrm{x}]$, só que ela vai andar no " $q$ " $[1 \leq \mathrm{x} \leq 10,-4]$, senão ela vai andar no " $r$ " $[10 \leq \mathrm{x} \leq 11,4 \mathrm{x}-44]$. Então vamos copiar a sentença de cada uma [Ficou assim " $\operatorname{Se}(0 \leq \mathrm{x} \leq 1,-4 \mathrm{x}, 1 \leq \mathrm{x} \leq 10,-4,10 \leq \mathrm{x} \leq 11,4 \mathrm{x}-44)$ ]. Vou dar um Enter. Vai juntar todas essas linhas (funções) aqui, e eu já posso fazer sumir [desabilitar] essas aqui [funções “p”, “q” e "r"]. Vai formar essa linha aqui [função por partes].
}

Tangram - Revista de Educação Matemática, Dourados - MS - v.4 n.1, pp. 134-154 (2021) 


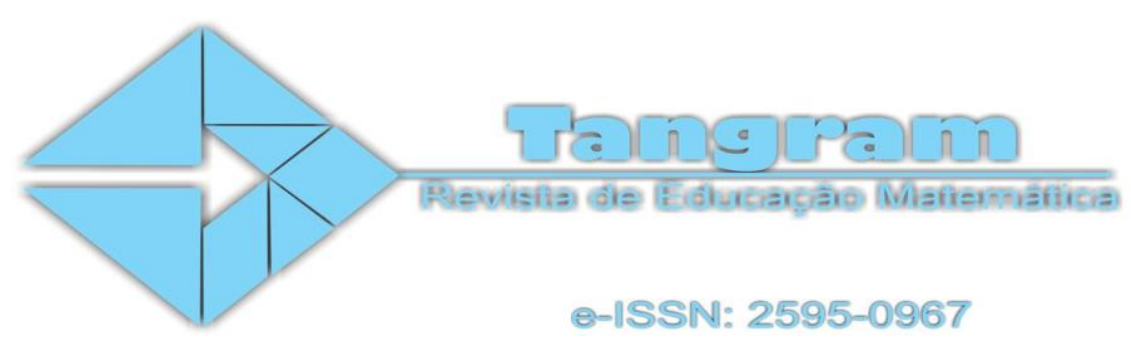

A aluna Manuela consegue descrever como é a conjectura utilizada no software para uma função por partes e qual será a representação gráfica desta função, ou seja, uma função constituída por partes, neste caso, de funções decrescente, constante e crescente, assim determinando o trajeto do submarino. Nesse sentido, o software permite elaborar e testar as ideias iniciais, formular conjecturas, trocando ideias com os colegas e a professora, e, validando-as, em suma, construindo conhecimento matemático.

No encontro seguinte, foi solicitado que os alunos da SRM respondessem algumas questões sobre funções de primeiro grau, em que observamos que o conceito de função não havia sido compreendido por eles, porque suas respostas foram vagas como a do Aluno 3 que respondeu que: "Função é uma reta sem começo e sem fim que tem seu local determinado pelas medidas de $x$ ”. Então, realizamos uma tarefa em que cada um dos alunos deveria escrever uma função do primeiro grau qualquer no GeoGebra, para que a pesquisadora, somente conhecendo sua lei de formação, lhes dissesse alguns pontos do plano que pertenciam a essa função. Nosso objetivo com esta tarefa foi analisar se os alunos conseguiam relacionar a lei de formação da função com os pontos sobre seu gráfico. Depois de um tempo observando as funções e os pontos pertencentes a ela, as Alunas 1 e 2 explicaram que para cada ponto temos um valor para x e outro para y, uma coordenada, e que para descobrir por quais pontos a função passaria era necessário colocar algum valor no lugar de $x$ na lei de formação, e então, calcular o valor de y. E assim seria possível saber as coordenadas dos pontos que pertenceriam a função. Foi sistematizado o conteúdo matemático com os alunos e solicitamos então que os alunos revissem suas respostas em que o Aluno 3 respondeu que função é: “Uma relação matemática entre duas variáveis sendo que o valor de y depende do valor de $x "$.

Então, verificamos que embora trabalhassem com as funções sem problemas, o conceito de função não havia sido compreendido, o que só se deu depois da sistematização do conteúdo pela pesquisadora, primeira autora deste trabalho, junto aos alunos, apoiado nas ideias utilizadas na construção dos cenários animados no software.

Tangram - Revista de Educação Matemática, Dourados - MS - v.4 n.1, pp. 134-154 (2021) 


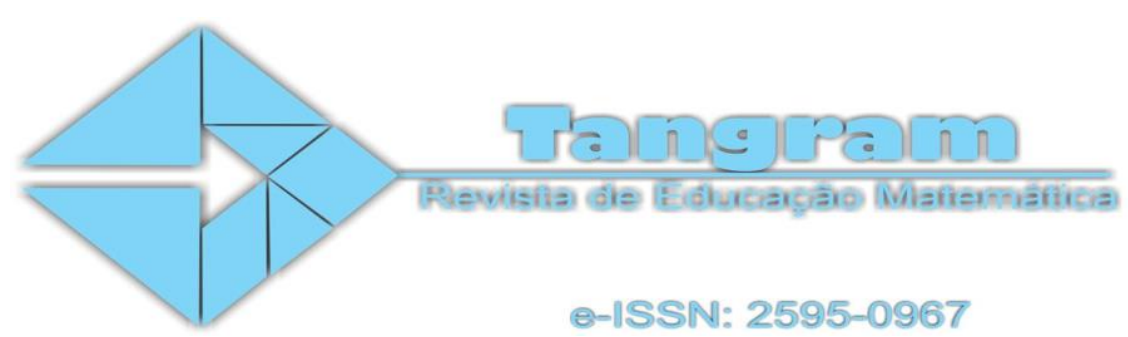

Aportados na Teoria dos Três Anéis de Renzulli (1978), observamos como os três fatores dos alunos com AH/SD interagem (habilidade acima da média, envolvimento com a tarefa e criatividade). Os alunos se interessam e se destacam em alguma área do conhecimento (Tabela 1), são participativos durante as aulas, questionam ou pedem auxílios quando não compreendem e se mostram interessados em concluir os cenários animados. Geralmente quando finalizam as construções propostas, buscam incrementar sua construção, usando a ideia original de um contexto e desenvolvendo em outro, assim produzindo novas ideias e possibilidades.

\section{Considerações Finais}

A pesquisa revelou que os alunos operavam com conceitos de função, por meio dos cenários animados no GeoGebra, antes de serem estudados na sala de aula regular dos respectivos anos em que estavam matriculados, dado que trabalhamos com alunos inclusive do sexto ao nono ano. Isto porque o GeoGebra favorece testarem suas ideias, formulando conjecturas e observando o que o software retorna, permitindo interpretarem o que está acontecendo, e assim chegarem as suas conclusões. Por exemplo, a representação algébrica de uma função crescente difere da de uma função decrescente pelo sinal do coeficiente angular, enquanto suas representações gráficas são inversas. Com os testes e investigações realizadas pelos alunos no software, permeadas pela mediação da pesquisadora, primeira autora deste trabalho, eles conseguiram associar as mudanças gráficas que ocorriam às alterações realizadas na parte algébrica das funções. Salientamos portanto, o papel do professor em questionar o aluno quanto ao que realiza e o que observa no software, promovendo a mediação entre o conhecimento matemático e o que o aluno digita no software e o que observa. A associação da parte algébrica a parte gráfica no GeoGebra permitiu que os alunos elaborassem e compreendessem conceitos, ao relacionarem os comandos inseridos e a construção gráfica das funções.

Tangram - Revista de Educação Matemática, Dourados - MS - v.4 n.1, pp. 134-154 (2021)

Este obra está licenciada com uma Licença Creative Commons Atribuição-NãoComercial-CompartilhaIgual 3.0 Brasil. 


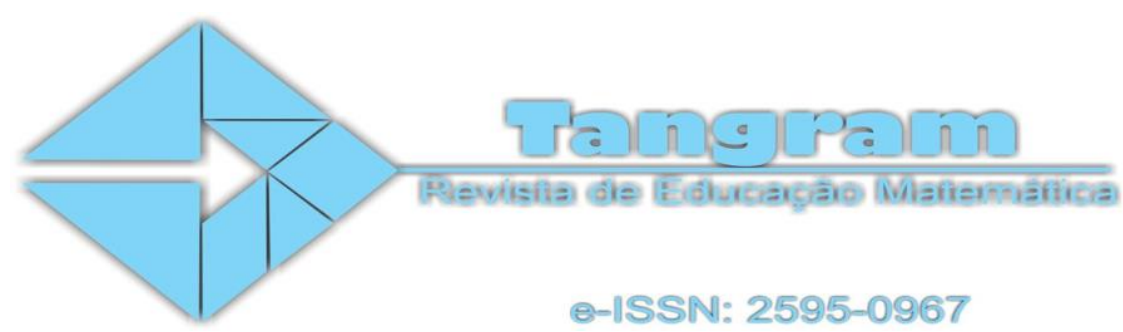

Identificamos nas explicações da aluna Manuela, que iniciou no projeto no ano de 2018 , que ela compreendeu conceitos matemáticos de funções importantes, como coeficiente angular, coeficiente linear, funções crescente, decrescente e constante, por meio dos cenários animados construídos por ela. Como observamos nos excertos das explicações, a aluna Manuela não utilizou algumas definições corretamente para se referir aos conceitos matemáticos, mas é preciso considerar que os cenários animados envolveram conceitos abstratos, que a aluna Manuela ainda não havia estudado em sala de aula regular, como conceitos de álgebra, incógnita e variável. Outro aspecto a ser destacado é que a aluna Manuela, em que nos focamos para realizar as análises, não possui indicativo de possuir AH/SD em ciências exatas, mas sim em linguagem, como apresentamos na Tabela 1.

Então avaliamos embasados nos relatos, registros e explicações feitas pelos alunos, que as construções de cenários animados contribuem para mobilizar conhecimentos matemáticos. Entretanto, cabe salientar a importância do papel do professor para mediar o conhecimento matemático, isto porque os alunos só compreenderam o conceito de função depois da sistematização do conteúdo como pode ser observado pelas respostas dos alunos que definiam função como retas infinitas, antes da sistematização, e depois compreenderam se tratar de uma relação entre duas variáveis. Então, a pesquisa apontou que a construção de cenários animados apresenta potencial para abordar conteúdos matemáticos, especialmente no que se refere ao de funções de primeiro grau investigado neste trabalho, visto que os alunos mostraram, por meio dos diálogos e construções dos cenários animados, compreender este conteúdo, suportados pelas mediações do professor para a significação dos conteúdos de matemática.

\section{Referências}

Brasil. (2006). Saberes e Práticas de Inclusão: desenvolvendo competências para o atendimento às necessidades educacionais especiais de alunos com altas habilidades/superdotação. 2 ed. Brasília: MEC, Secretaria da Educação Especial.

Brasil. (2008). Ministério da Educação, Secretaria de Educação Especial. Política Nacional de Educação Especial na Perspectiva da Educação Inclusiva.

Tangram - Revista de Educação Matemática, Dourados - MS - v.4 n.1, pp. 134-154 (2021) 


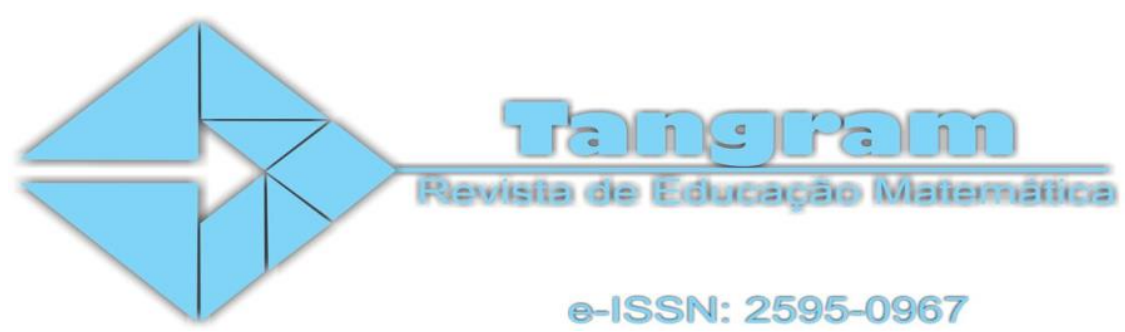

Brasil. (2010). Manual de Orientação: Programa de Implementação de Salas de Recurso Multifuncionais. MEC, Secretaria da Educação Especial.

Brasil. (2018, 25 de fevereiro). Programa Implementação de Salas de Recursos Multifuncionais. http://portal.mec.gov.br/pet/194-secretarias-112877938/secad-educacao-continuada223369541/17430-programa-implantacao-de-salas-de-recursos-multifuncionais-novo. Ministério da Educação. Consultado em 25 fevereiro de 2018.

Cyrino, M. C. C. T., Oliveira, H. M. (2016). Ensino Exploratório e casos multimídia na formação de professores que ensinam matemática. In: CYRINO, M. C. C. T. (Org.). Recurso multimídia para a formação de professores que ensinam matemática. Londrina: Eduel, p. 19-32

D’Ambrósio, B. S. (1989). Como ensinar matemática hoje? Temas e Debates. SBEM. 2(2), 15-19.

Delpreto, B. M. L, Zardo, S. P. (2010). Alunos com altas habilidades no contexto da educação especial inclusiva. In: Delpreto, B. M. L, Giffoni, F. A., Zardo, S. P. (Org). A Educação Especial na Perspectiva da Inclusão Escolar: altas habilidades/superdotação. Coleção A Educação Especial na Perspectiva da Inclusão Escolar: Ministério da Educação, Secretaria de Educação Especial, Universidade Federal do Ceará, 2010. v. 10. p. 19-27.

Fleith, D. S. (2006). Criatividade e altas habilidades/superdotação. Revista do Centro de Educação, Brasília - GO, (28). http://dx.doi.org/10.5902/1984686X

Guimarães, G. R., Mello, R, M. (2006). Grupo de trabalho sobre altas habilidades/ superdotação. Curitiba: PR.

Mendonça, L. D., Zavitoski, P., Capellini, V. L. M. F. (2013). O que os professores compreendem por altas habilidades/ superdotação? VIII Encontro da associação brasileira de pesquisadores em educação especial, 2013. Londrina, nov. 2013. 2930-2940.

Mosquera, J. J. M., Stobäus, C. D., Freitas, S. N. (2013). Altas habilidades/superdotação: abordagem ao longo da vida. Revista Educação Especial, Santa Maria - RS, 26(46), p. 401-420. http://dx.doi.org/10.5902/1984686X

Onder, A. D. (2009). O Olhar do Aluno Para a Matemática. IX Congresso Nacional de Educação, 2009, Curitiba. Curitiba: Champagnat.3564 - 3575.

Ponte, P. P. (2006). Estudo de Caso em Educação Matemática. Bolema, 25, 105-132.

Procópio, W. (2011). O Currículo de Matemática do Estado de São Paulo: sugestões de atividades com o uso do GeoGebra. Dissertação de mestrado em Educação Matemática, Pontifícia Universidade Católica de São Paulo.

Tangram - Revista de Educação Matemática, Dourados - MS - v.4 n.1, pp. 134-154 (2021) 


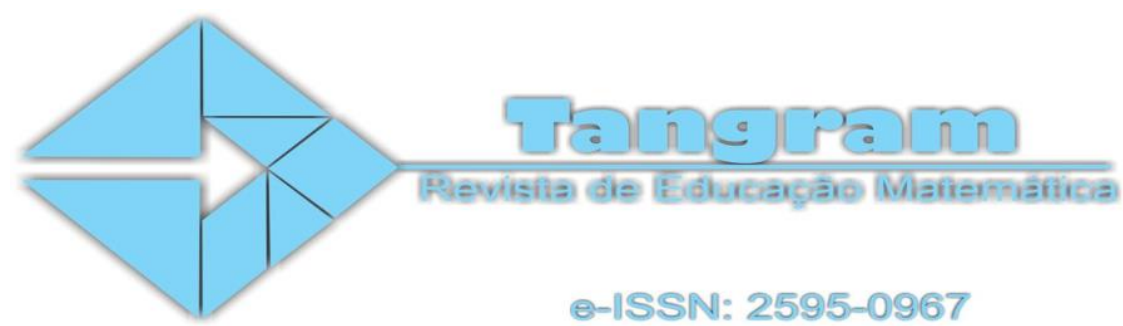

Renzulli, J. S. (2004). O que é esta coisa chamada superdotação, e como a desenvolvemos? Uma retrospectiva de vinte e cinco anos. Educação, Porto Alegre - RS, (1), 75 - 121, ano XXVII, jan/abr. 2004. Tradução de Susana Graciela Pérez Barrera Pérez.

Renzulli, J. S. (1978). What makes giftedness? Reexamining a definition. Phi Delta Kappan, 60(261), 180-184.

Santa Catarina. (2011). Altas habilidades/Superdotação rompendo as barreiras do anonimato. Secretaria de Estado da Educação. Fundação Catarinense de Educação Especial.

Valente, J. A. (1993). Diferentes usos do computador na educação. Em Aberto, Brasília, 12(57), 216.

Virgolim, A. M. R. (2007). Altas habilidade/superdotação: encorajando potenciais. Brasília: Ministério da Educação, Secretaria de Educação Especial.

Yin, R. K. (2001). Estudo de caso: planejamento e métodos. 2a ed. Porto Alegre: Bookman.

\section{Agradecimentos}

Ao CNPQ - Conselho Nacional de Desenvolvimento Científico e Tecnológico.

Contribuições dos Autores

$1^{a}$ autor: conceitualização; curadoria de dados; análise formal; investigação; metodologia; administração do projeto; visualização; redação - rascunho original; redação.

$2^{\text {o }}$ autor: conceitualização; curadoria de dados; análise formal; metodologia; supervisão; visualização; redação - rascunho original; redação - revisão e edição.

Tangram - Revista de Educação Matemática, Dourados - MS - v.4 n.1, pp. 134-154 (2021) 